\section{Junior scientists are denied access to data, says survey}

Rex Dalton, San Diego

A quarter of trainee scientists have had requests for data denied, according to a survey of more than 1,000 researchers at 50 of the largest research institutions in the United States.

The study, which is the first attempt to estimate the extent to which doctoral students and postdoctoral fellows suffer from data-withholding, found that $23 \%$ of respondents were denied results, materials or other information related to published research. Of the three disciplines surveyed, life sciences (27\%) had greater difficulties than chemical engineering and computer science (20\%).

Withheld data delayed respondents' research by about four months on average, says Eric Campbell, a sociologist at Harvard University who discussed the results on 12 November at the Office of Research Integrity's conference in San Diego. Campbell and his colleagues have charted data-access issues for several years (see Nature 404, 6; 2000), but this is the first study to focus on $\mathrm{PhD}$ students and postdocs.

Campbell did not discuss why the data were being withheld, but said that he had considered and rejected various explanations during the study.

Restrictions due to medical privacy or industrial contracts, for instance, could not account for the pattern of data-withholding observed, Campbell says.

The survey, which was sponsored by the Office of Research Integrity, could help raise awareness of the data problem. When the study began early last year, Campbell says that one university department chairman told him: “Trainees don't know anything about data being withheld from them; why would you want to ask them?"

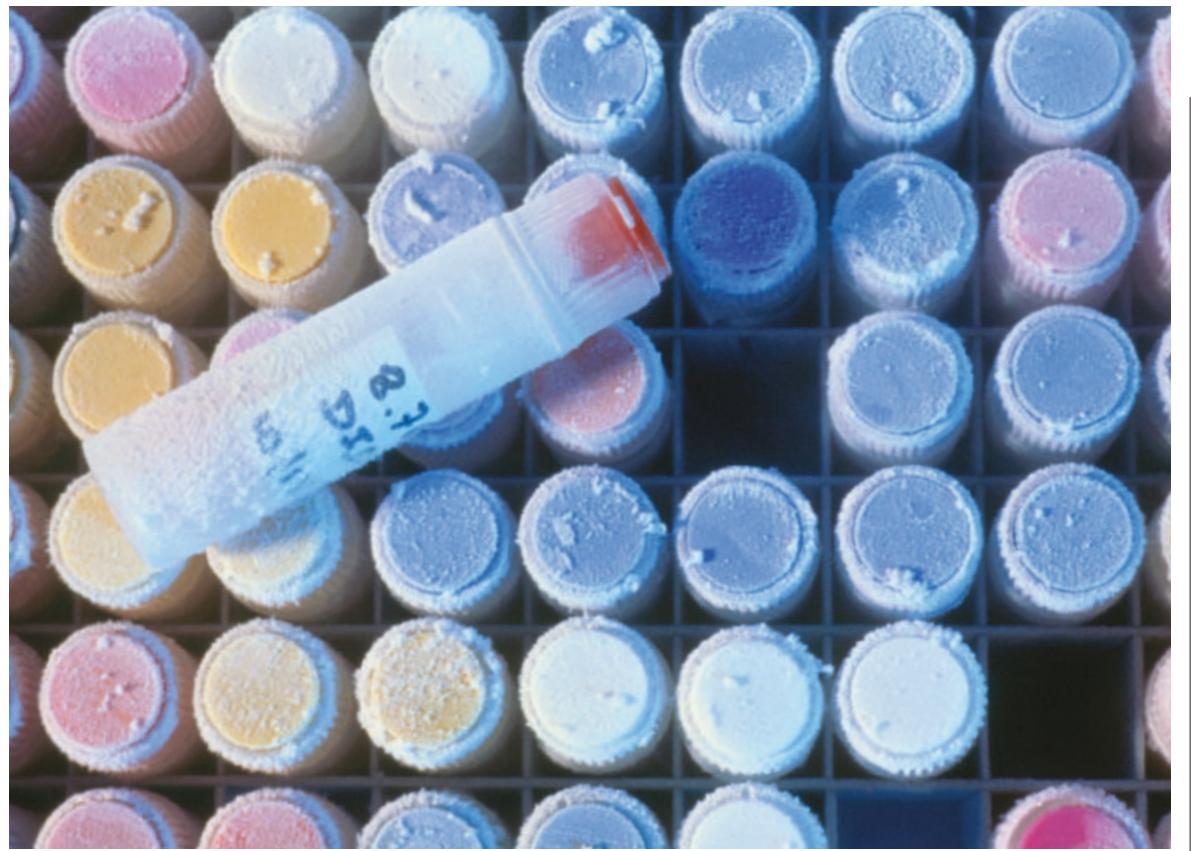

Hard cell: tissue banks store vast quantities of material but organize it in different ways.

\title{
Summit calls for clear view of deposits in all biobanks
}

Helen Pearson, New York

Action must be taken to coordinate humantissue banks if these resources are to be exploited to the full, researchers said at a meeting last week.

In recent years there has been a huge increase in the number of biobanks collections of tissue or DNA samples matched with health records. The samples should allow disease susceptibilities and drug responses to belinked to variations in genes or proteins. Yet little has been done to maximize the banks' potential by ensuring information can be shared between them, say researchers who met at the Biobank Summit in Tarrytown, NewYork, over 15-17 November.

"All the effort and immense public money will be wasted if we can't combine certain elements," says Bartha Knoppers, a bioethicist at the University of Montreal, Canada.

Problems with biobanks will arise, researchers say, because each one tends to have a different system for collecting, processing and storing tissue, logging medical histories and obtaining patient consent. They also use different computer systems and codes to store information.

These differences could hamper a scientist who wants to pool sufficient patients to study a rare cancer, for example. Tissue samples in two biobanks may be impossible to compare if they have been processed using different chemicals. And medical histories could be worthless if they use differing terminology or lack essential information about diet or lifestyle.

Some kind of international coordination is "extremely important if we are ever going to understand health on a big scale", says JanEric Litton, director of informatics at the Karolinska Institute Biobank in Stockholm, Sweden.

A few collaborations are emerging. Last year, Knoppers and others started the Public Population Project in Genomics, which aims to build a database of reference documents on best practices for collecting samples, medical histories and consent. The project received seed funding last week of Can $\$ 1$ million (US\$0.8 million) from Génome Québec and Genome Canada.

Another group is focusing on cancer biobanks around the world. It plans to meet in early 2005 to discuss how to ensure that information can be exchanged. "We have to act pretty soon on this," says Anna Barker of the National Cancer Institute in Bethesda, Maryland, who heads a programme to build a US cancer-patient biobank and is helping to organize the cancer group's meeting next year.

Such moves are urgent because of the plethora of biobanks springing up around the world. Britain, Estonia and Sweden are among the countries creating huge, government-sponsored biobanks. Countless more are being built up by academic groups, nonprofit organizations and the biotechnology and pharmaceutical industries.

Yet most researchers have been too focused on establishing their own biobanks to think much about linking up with others, delegates said at the meeting. "We will be playing catch-up," says pathologist Carolyn Compton of McGill University in Quebec, Canada, "but it is doable." 